\title{
Co-Designing for Rightful Presence in Informal Science Learning Environments
}

\author{
Angela Calabrese Barton | ORCID: 0000-0002-9555-5214 \\ Corresponding author, \\ Educational Studies Department, School of Education, \\ University of Michigan \\ Ann Arbor, MI 48109, USA \\ angiecb@umich.edu
}

Won Jung Kim | ORCID: 0000-0002-3914-6854

Department of Curriculum, Instruction, and Teacher Education,

Michigan State University

East Lansing, MI, 48223, USA

kimwonı@@msu.edu

Edna Tan | ORCID: 0000-0002-4583-4557

Department of Teacher Education and Higher Education, University of North Carolina at Greensboro

Greensboro, NC 27402, USA

e_tan@uncg.edu

Received: 14 July 2020 | Revised: 25 September 2020, 13 November 2020 | Accepted: 23 November 2020

\begin{abstract}
Addressing ways in which systemic injustices manifest in learning environments has been a significant challenge to the field of informal science learning (ISL). The dominant discourses of equity are framed around calls for inclusion and the extension of rights for quality learning opportunities for all youth. In this paper, we move beyond inclusionary approaches to use the justice-oriented framework of rightful presence. Grounded in participatory design research, the findings show how possibilities for rightful presence arise when educators and youths collaboratively engage in exposing,
\end{abstract}


disrupting, and transforming unjust narratives and practices that position youths as knowledge recipients and temporary guests in the host ISL institutions. These possibilities are characterized by opportunities to foreground youths' lived lives and community wisdom in ways that shift the boundaries of who and what science is for. We discuss insights, dilemmas, and implications regarding justice-oriented pedagogies and their possibilities for rightful presence in science education.

\section{Keywords}

equity - justice - informal science learning - rightful presence - participatory design research

\section{Introduction}

We aim to advance understandings of what a justice-centered perspective in informal science learning (ISL) is or could be through the lens of rightful presence, and its implications for the design of ISL programs and pedagogies. Consider the following:

Like, the most important part of STEM Club is that it's not judgmental. Like nobody judges you here. You can just be yourself. You can use your ideas to make things, and your ideas are good. And you can learn a lot. You can also just be with your friends. Like everyone in here cares about each other. We call it "Green Club Love."

LOUISE, age 12

Louise shared these words about her afterschool sTEM club. She calls attention to feeling welcomed, having her ideas valued as she learns and engages with STEM, ${ }^{1}$ and the importance of friends. These feelings stand in contrast to how she described "the most difficult year" at school. In sixth grade, there was "too much drama" and "no one liked me in my classroom."

Louise's comment speaks to why it is important to focus on youths' rightful presence in ISL. Having a rightful presence in ISL means that the ISL learning

1 We use the term "STEM" to refer to the integration of engineering into K-12 science learning as outlined in the Next Generation Science Standards. We alternate science and STEM. We do not refer to STEM as science, technology, engineering, and mathematics. 
community, through its discourses, practices, and relationalities, supports the on-going political struggle for belonging because of who one is and not who one is expected to be (Calabrese Barton, \& Tan, 2020a). This stance foregrounds how legitimately belonging in a community of practice is informed by the historicized injustices outsiders have encountered in relation to participation in community. It also foregrounds the ways in which individual experiences of injustice intersect with systemic injustice through sanctioned power hierarchies and practices.

Yet despite the promotion of community-based ISL opportunities, there has been little research that focuses on the design of pedagogical practices that support these more justice-oriented aspirations. We ask the following research questions:

RQ1: How do youth bid for a more rightful presence in ISL?

RQ2: How do ISL educators recognize and respond to such bids? We use the word "bid" to mean how youth solicit for, in their words and actions, a more rightful presence.

Louise's experiences are not unique. Many youth bid to be welcomed as a whole person with valuable knowledge, practices, and experiences that matter in STEM. ISLS have been held up as spaces that promote greater equity in ISL opportunities. Many programs are built around youths' interests, and reach them during pivotal times in their academic trajectories, such as the middle grades (ages 11-14). However, the wide range of ISL programs and practices that reach different audiences are often accessible, connected, or empowering for only some participants, and full participation is sometimes limited for minoritized youth because of the cultural norms of programs. As in schools, cultural and linguistic assumptions are made in informal environments in ways to welcome some participants while excluding and alienating others (Dawson, 2014).

We take up these questions in the context of a summer sTEM-rich making camp located in a Midwestern community center in a mid-sized city in the US. We conducted this work in collaboration with partnering youths (ages 11-13), taking a historicized and future-oriented ecological and participatory design approach (Gutiérrez et al., 2017). We take the stance that educators and youths are co-learners, co-disruptors, and co-creators of a more just world with and in ISL. Grounded in participatory design research, the findings show how possibilities for justice-oriented ISL arise when educators and youths collaboratively engage in and amplify youths' bids for rightful presence in science and learning operating in their lives. 


\section{Justice and Informal Science Learning}

\subsection{The Limits of Inclusion}

ISL settings provide pathways into STEM for many young people (Tan et al., 2012). Free from structured expectations of specific standards, testing, and constrained time, ISLs have provided many youth, across demographic groups and geographic locations, with a multitude of opportunities and resources to learn and engage in STEM in ways that formal schooling has not made possible. The focus of these ISL programs tends to be to inspire and inform young people about science and possibilities for futures trajectories in science (Archer et al., 2016).

The field of ISL has primarily focused on access and opportunity as its central equity charge (Feinstein, 2017). This work has yielded powerful insights into how economic (e.g., entrance and travel costs), geographic (e.g., location and travel challenges), physical (e.g., accessibility), and social and cultural (e.g., normative and exclusionary language, assumptions, norms, values, and representation) dimensions work individually and together to foster inequitable opportunities, especially along race and gender lines. Dawson (2014) illustrates how practices of educators in science museums and science centers "reinforced" participants' "preexisting sense that museums and science centers were 'not for us"' (p. 981). For example, the museums and science centers presupposed a mastery of the English language and British customs in the display of exhibits, inhibiting visitors' opportunities to use, understand, and learn from the displays. Visitors were further alienated by museum staff, who embodied dominant and repressive norms by scolding younger visitors and assuming background knowledge. These studies help researchers better understand how ISL may oppress groups of people based on race, ethnicity, and language, and the forms these systems of oppression take place in local practice.

Other studies have shown similar findings. For example, in a study tracing youths' pathways in ISL, researchers showed how youths perceived ISL structures to feel like school (Greenberg, 2019). Dewitt and Archer (2017) point out that even when access to ISL is leveled, differences in participation, in both quality and quantity, varies in ways that favor White, male, and economically advantaged children. Thus, even when youths gain access to ISL programming, they often experience exclusionary patterns of practice similar to those found in formal environments, such as learning experiences that do not leverage their lived experience as valued learning resources. Simply having fair access to ISL opportunities does not in itself promote just patterns of participation. Inclusion and participation in ISL are often patterned hierarchically, elevating the discourses and practices of masculinity, heteronormativity, and Whiteness. 
If equity is to be achieved, then attention needs to be paid to the ways in which injustices are built into the system of ISL - the discourses, practices, norms and relationalities - and how these play out in local practice (Archer et al., 2016). Without attention to how youth are expected to participate, the ways in which programs systemically include or exclude youths through discourses and practices remain unexamined (Shea \& Sandoval, 2019).

\subsection{Taking a Justice Stance}

There is a growing body of innovative, equity-focused research and development work conducted in ISL contexts that shows how some ISL spaces can and do successfully engage and support youths from non-dominant communities in science. This work draws attention to how these spaces support not just science-orientated goals (such as science learning and/or science-related pathways) but also critical agency and recognition in ways that support and value the young people and their communities (Calabrese Barton \& Tan, 2010; Rahm, 2010). For instance, Calabrese Barton and Tan (2010) show that youths can be supported to develop science identities when they have opportunities to leverage their lived experiences and community wisdom as an integral part of doing science and engineering - when they receive recognition for this. Moreover, youths can increase their learning, engagement, and agency in STEM when they are supported to challenge dominant master narratives in STEM and break down hierarchical binaries of what knowledge, experiences, and voices matter in STEM (Birmingham et al., 2017). Works like these highlight the importance of asset-based and participatory approaches, which seek to respect and value youths' community knowledge and resources, in refusal of damage-centered research (Tuck, 2009). To advance the field of ISL, attention therefore needs to be paid to the limits of inclusion.

The basic rights to a high-quality learning are grounded in the dominant discourse and practice of schooling and of STEM, which reflect White and Western ways of knowing and doing. The way that STEM is often taught in ISL and how youths are expected to learn further projects these dominant cultural norms (Bevan et al., 2018). Equity as inclusion may extend the right to participate in ISL, but it does not account for whose values undergird these rights. Who does one need to be to fully receive these rights? Whose values, beliefs, and ideals undergird these rights? Extending rights only provides resources and approaches for making participation in the current constructions of classrooms and disciplines possible. Indeed, how these rights are extended and enacted can make a difference in whether or not a youth is welcomed as a fully legitimate member of the community. Furthermore, the extension of rights to youth is built around individualized notions of justice-to-come, abstracted 
from the power relationalities of teaching and learning STEM in informal contexts.

One way to think about this is in how equity as inclusion is built on the guest-host relationship model (Calabrese Barton \& Tan, 2020a). Youths, as guests in their ISL communities, are expected to follow dominant routines and practices with the threat of disciplinary or other sanctions for non-compliance while being historically marginalized in STEM because of their race, immigration status, language, class, and/or sexuality. Although minoritized youths have powerful cultural knowledge and experience in the world, including their families' and communities' cultural practices, which are highly relevant to engaging with STEM, many youths remain outsiders to ISL because of the dominant discourse, practices, and norms of the field.

Being an outsider means more than not having one's experiences, knowledge, or practices valued in the learning community. When youth are positioned as outsiders because of who they are and the cultural assets they bring to learning, they are made invisible: They are made "missing" (Tedesco \& Bagelman, 2017). They are continually de-humanized and positioned without important forms of power and authority, significantly limiting or completely denying opportunities to be important contributing members of the learning community in ways that support their own growth and development, that of others, and the social context in which learning takes place. In this way, youths have been denied a "rightful presence" in their learning community.

\subsection{Why Rightful Presence?}

For many young people, engaging in ISL can be constrained and limited. Consequently, not all youth are encouraged or supported in leveraging their powerful cultural expertise towards meaningful learning or engagement in ISL. We can think about this as denying youth rightful presence in ISL (Calabrese Barton \& Tan, 2020a).

By rightful presence in ISL, we refer to youth having legitimate membership in a learning community because of who one is, and not because of who one should be. In ISL spaces working toward rightful presence, members of the learning community collaboratively support re-structuring power dynamics in more just ways. Members of the learning community do this by working to acknowledge the injustice youth experience, and explicitly focusing on the possibilities of disrupting these injustices and working towards social transformation. In other words, rightful presence is a critical mode for making "present" those who have been made "missing" by the forms of racialization and colonization manifest in schooling.

Who youth are and want to be would look different in learning communities if they were more than guests, in other words, if the young people had a 
rightful presence in their learning communities. We suggest that to advance the justice-centered concerns of ISL, it is important to design for youths' rightful presence. The challenge is in imagining and enacting what this may look like. In earlier work (Calabrese Barton \& Tan, 2020a), we describe how rightful presence in learning environments is enacted through a set of three tenets:

- Tenet 1: Allied political struggle is integral to disciplinary learning: the right to re-author rights

- Tenet 2: Rightfulness is claimed through presence: making justice/injustice visible

- Tenet 3: Collective disruption of guest/host relationalities: amplifying the sociopolitical

First, when we say that allied political struggle is integral to disciplinary learning (e.g., STEM), we mean that educators and youth work together to challenge and transform what participation in the disciplines entails or what meaningful representations of learning look like in ways that humanize participation and value youth as cultural and whole people. We call this re-authoring rights because these disruptions and transformations change whose knowledge, practices, and experiences matter. It is insufficient - and unjust - to simply ask youth what rights they think need re-authoring, as they may not know immediately. We have to be attuned to what youth bring to ISL and we have to design learning spaces and processes in ways that allow for this to emerge.

Second, when we say rightfulness is claimed through presence, what we mean is that the whole of youths' lives - and that which makes participation in ISL empowering and marginalizing - become a visible part of learning: It becomes the stuff upon which meaningful learning is built. This also means making the work of justice happen in the here and now - in this moment in this learning environment rather than in some abstracted future (e.g., "if you learn what I am telling you know you could be a scientist one day"). Orienting towards the future is important, but so is the present.

Last, by collective disruption of guest/host relationalities, we mean that the responsibility for disruption and transformation is borne by all members of the learning community, educators and youths alike, not just borne by those who have been marginalized. This kind of power sharing is important because it helps to create new and different spaces for making visible youths' lives, as we noted in Tenet 2.

\subsection{What Do These Tenets Look Like in Practice in ISL?}

Consider Sincere's experiences. Sincere is bright, popular among his peers, funny, and very inquisitive. As he said of himself, "I'm not a nerd, but I'm not average either. I'm a goofy kid that still gets the job done. Efficiently, and well." However, Sincere experienced structural and symbolic racism in his 
life, limiting opportunities to rightfully belong in science. One of his teachers labeled him a disruptive "problem that needed solving." He had a record of getting in trouble, preventing opportunities to participate in enrichment programs. He was suspended from his club for a period of time for walking rather than taking the bus after school. However, Sincere told us that if he had "better snack options" at the club, he would feel less tempted to "run away" to the store. Even though he wanted to be an architect when he grew up, he felt that school science and math was boring because they never covered topics he was interested in or felt he needed for his future career.

In his ISL program, Sincere designed and prototyped what he called a "high tech" greenhouse, starting with a donated indoor tower garden. During the design process, his afterschool educators created pedagogical space for Sincere to make visible and take action on his concerns about access to quality food as central to STEM. They encouraged Sincere to identify an issue he wanted to work on. When he chose the topic of access to quality food, they helped him to design and administer a survey to garner information from club and community members about food access and sustainability and community health. They encouraged Sincere to use the words and ideas shared by his community participants, in combination with the science, as evidentiary bases for project design. They taught Sincere how to use GIS mapping to visually illustrate the extent of his local food desert, and then to conduct research on how his own experiences map onto a history of injustice, as a disproportionate number of Black and Brown youth in the US live with food insecurity. They created spaces for Sincere to design experiments that would allow him to tailor the greenhouse to the needs of his peers and community. For example, because his peers wanted to be able to eat "healthy takis" (a spicy corn chip snack), his educators helped him to investigate the growing conditions needed for the lettuce, herbs, peppers, tomatoes, and onions he wished to plant.

Sincere's experiences with the greenhouse project give a glimpse into working towards rightful presence in ISL. First, Sincere's idea of care was nested in his understandings of the needs of the young people in his community. By welcoming these needs as integral to science, Sincere's afterschool educators created a space that made it possible for the rights to participate to become re-authored (Tenet 1). The epistemological basis for Sincere's project was more than the scientific and engineering dimensions of making: It was routed in Sincere's embodied knowledge of young people, like himself, as hungry after school with few healthy and substantive choices available. As Sincere noted in his interview, he also felt his idea for the greenhouse would help his whole neighborhood by "providing to the poor and humans in need," and helping his "city's reputation." 
Second, his educators helped Sincere to make sense of his community needs in a historicized way. They helped Sincere to see how his experiences were shaped by a history of systemic injustices, and how acting on his own experiences also meant acting on the larger injustice (Tenet 2). This collective engagement among young people, educators, and community members to name the focus of their STEM investigation reflects the importance of Tenet 1 , the right to re-author rights, as authority to name the relevant STEM issues shifted from the educators or the field to the young people and community members. It also reflects the importance of Tenet 3 , where these processes were collectively engaged, removing the responsibilities (and the accompanying decades of injustice) from the young shoulders of Sincere.

In this process, Sincere not only deepened his STEm learning, he did so in a way that centered and amplified his understandings of and connections to his community. Indeed, the very idea for the greenhouse was grounded in Sincere's desire to make something that would be helpful to his friends and people in his community. Being helpful was both a desire to care and a desire to disrupt and transform conditions.

\section{Purposefully Designing for Rightful Presence: The Case of STEM Camp}

In this section, we introduce how we sought to purposefully design an informal sтEM program aimed to help educators and youths alike make visible and amplify youths' rightful presence. While Sincere's vignette describes how rightful presence can emerge through the vision of justice shared among youths and educators, such vision and associated efforts do not naturally occur, but require intentional design work. To engage in the ongoing processes of designing, critiquing, revising, and reflecting on, we conducted a participatory design research study of the summer STEM camp program.

Participatory design research attends to power dynamics that operate in social relations and discourse among different participants engaged in the interventions, such as the researcher/researched binary and beginner/experienced researcher hierarchy. Paying attention to the power dynamics, processes of participatory design center the questions about who participates in knowledge generation, how, and to what ends. It also centers the importance of critique and social transformation. In this approach, the epistemological authority positioned with roles such as researcher and designer is purposefully deemed porous and open to question in ways that foreground the knowledge and wisdom of community members with/for which the participatory design 
approach is implemented (Zavala, 2016). The primary object of analysis in participatory design is making visible the processes of participation in design practices, the moment-to-moment interactions and tensions, and consequential (trans)formation of participant relationships (Vakil et al., 2016).

\subsection{Context:Designing for Rightful Presence via Research-Practice Partnership}

This study is situated in a larger research-practice partnership in which we have collaborated with youth, informal educators, and directors in the local science/community centers for the past 5 years. Both Louise (opening quote) and Sincere (previous vignette) were members of the centers' ST EM clubs. The partner centers are located in Great Lakes City, a mid-sized city in the Midwest. Our project focused on identifying and analyzing the instantiations and consequential impacts of informal educators' pedagogical practices in youths' STEM programs (Kim et al., 2019; Ryoo \& Kekelis, 2016), through which we developed a set of initial principles we hope to ground for designing programs and practices aimed at youths' rightful presence, as described below. At the time of this study, we were promoting ways to design, implement, reflect on, and revise programs by applying these principles. The summer sт EM camp program this study introduces is a participatory design initiative held in August 2019.

\subsection{Participants}

In the summer STEM camp program, eight youths and two adults participated. All the participating youths, who had been long-term participants in the community center's ST EM club, were Black, ages 11-13, and voluntarily participated in the summer STEM camp. Also, we co-facilitated the program, playing multiple roles: adults learning with and from youths, educators facilitating the program, and researchers (as the first and second authors of this study).

Angie is a White woman, who studied and taught formal and informal sтEM education, and was a long-term STEM club educator in the community center. She has collaboratively designed, taught, and studied with youths and community educators at the community center for 14 years. She was the center's director and co-started the research-practice partnership project in which this work took place. In this summer STEM camp, Angie took multiple roles: (1) seeking to learn by applying the design principles into new programs, (2) creating an ISL space in which youths exercise rightful presence, and (3) supporting Won, a new researcher to the field, to engage in ISL practice and critically reflect on the practice together.

Won joined the research-practice partnership project as a doctoral scholar for two years, and sought to take both the educator and researcher perspective 
by participating in the participatory design project with Angie. Before joining the project, she worked as a secondary science teacher in Korean public schools for 12 years. While she tried to support youths' rigorous engagement in science and finding its relevance within their lives, the concept and practice of rightful presence and justice-oriented science education were new and unfamiliar pedagogical frameworks. She resonated with the lives of the young people of Color, and was willing to learn with and from the young people.

\subsection{Our Participatory Design Principles}

Our participatory design of programs, including the sTEM camp of this study, was grounded in the tenets of rightful presence undergirded by the stance shared by the research-practice partnership members that educators and young people are co-learners, co-disruptors, and co-creators of a more just world with and in ISL. We sought to enact the tenets of rightful presence into our pedagogical practice deliberately and regularly in our daily routine and over time, with three particular practices as our design principles.

\subsubsection{Co-Creating Opportunities for Critical Dialogue}

A central design principle is educators and young people working together to critically make sense of their ISL experiences and programs, and revising and refining the design in on-going ways. For example, to support critical dialogue, educators solicit youths' experience through sessions of co-planning and daily group conversations. They regularly checked in with young people before, during, and after program sessions, and asked youths for multi-modal feedback including weekly exit passes, image/video dairies, and Google forms. Central to this principle is using this input to make visible youths' rightful presence, their lives, communities, histories, presents, and desired futures as inspirations and starting points of co-creation (connections to Tenets 1 and 3).

\subsubsection{Reclaiming Space and Narratives about Who Authors Science Learning}

The second design principle is that of reclaiming space and narratives about who authors science learning (e.g., Calabrese Barton et al., 2020b). By "authoring," we emphasize the right to create, revise, and expand the meaning of learning and becoming in science. This requires educators to decenter their traditional norms as prescribers of youths' learning, which comes with tension and political struggles intersecting with normative sociocultural and historicized structures. To act on this principle, educators solicit for community wisdom as integral to the social, physical, and representational dimensions of ISL engagement. Reclaiming often initiates with naming and documenting how 
the spaces of ISL and the ways the narratives that are produced with and in those spaces have maintained injustices. Such an exposure of multiple scales of injustices may prompt educators and youths to disrupt them by actively changing the space and narratives both immediately and consequentially (connections to Tenets 1 and 2).

\subsubsection{Critically Being With}

"Critically being with" is a principle that involves bearing witness to the historicized and perpetuated racism and other forms of injustices youths and community members seek to disrupt and transform (Villenas, 2019). Critically being with is particularly important as youths' political struggle for rightful presence often comes with instances that occur beyond what educators can imagine. Particular attention is required to recognize and co-disrupt the boundaries of race, gender, class, and age that members present in the science learning space seek to push against. One way to facilitate this principle is to support youths to have the freedom to raise critiques and concerns without fear of repercussion and create trust that their educators would take up the youths' critiques and concerns with care and respect (connections to Tenets 2 and 3 ).

\subsection{How We Enacted These Principles}

We describe how we enacted these principles in (3.4.1) shaping our initial ideas of the STEM camp program and (3.4.2) engaging with young people in daily critical dialogue.

\subsubsection{Shaping Initial Idea of the stem Camp Program}

As researcher-educators, we sketched up initial ideas later developed into a program called World From Different Views. The conception of this program idea had two grounds. First, we sought to leverage the interest in and experiential knowledge of visual devices that the youths had expressed and that Angie had observed during the prior semester club sessions (e.g., camera and filter functions in their smartphones, portable video-recorders used during the sessions, and drones). Building on these, we conceived a program to investigate STEM-related aspects of the devices. We attended to how the devices were contemporary STEM artifacts historically developed from basic types of cameras such as pinhole and film cameras. Thus, we further imagined supporting youths to review both the historical and contemporary devices, giving emphasis to STEM investigation and making/engineering experiences (e.g., pinhole cameras made from recyclable materials, film camera dissection, remotecontrolled cars with portable cameras, and drone operations). 
Second, the program idea was grounded in our hope of helping youths acknowledge and use the multiple perspectives that the devices make visible to humans. We planned a week-long project of coding GIS maps using images the youths would generate with the visual devices they would modify or create. By eliciting the youths' consideration of different perspectives (e.g., how animals such as birds in the backyard, pets at home, and insects in the woods see the world), we hoped to support youths to use STEM learning to disrupt the normalized ways of viewing the world. As we considered our camp a metaphor for disrupting the dominant perspectives of seeing the world, we encouraged the youths' ongoing examination and disruption of any aspects of the program that they found to be sites of injustice and thus transformation.

One crucial point relevant to RQ1 (How do youth bid for a more rightful presence in ISL?) is that the initial program idea was grounded in our attention to youths' bids for rightful presence, which we consider manifested through the youths' interests, experiential knowledge, and passion for making. We, as educators and researchers, shared responsibilities to support youths' bids for rightful presence by foregrounding what youths indicated mattered to them and incorporating that into rigorous engagement with ST EM. While we brought to the camp the initial ideas we had prepared for the youths, the initial ideas were open to youths' transformation. Youths participated as experts in the processes of designing and creating the program, including critiquing, revising, refining, and rejecting, and suggesting a new activity and program.

An additional point relevant to RQ2 (How do ISL educators recognize and respond to such bids?) is that the learners from this STEM camp were not only the young people but also the educators. As our findings illustrate, the young people taught us by taking actions that led to authentic scientific investigation, through which they made visible their rightful presence. Youths' actions in the moment made us reflect on educators' pedagogical talk-moves and more actively participate in the youths' political struggles to become rightfully present. In short, we considered our participatory approach to be collective learning and disruption of hierarchical and discriminatory narratives about who legitimate knowledge creators are and what it means to create knowledge.

\subsubsection{Circle Time on the Red Couch}

One crucial example of how we incorporated the design principles into our daily routine was something the youths affectionately called "circle time on the red couch." It was an important cultural-historical practice that had been developed, over time, by the afterschool and summer STEM camp. During circle time, the youths and educators pulled chairs into a circle where they sat 
together for discussion. We discussed activities of the day and future directions, exchanged feedback about each other's design/making artifacts, and often shared experiences and feelings of how their days were going. In particular, circle time incorporated the red couch and the rainbow carpet since the youths declared this was where they felt included and able to be themselves. Youths selected the red couch by themselves ("it was the kids' idea to have a couch in here") and considered it their home-space ("we can take a nap on the couch" or "when it's OK if we're upset, and you like let us talk it out," "more like home," "not like school").

As such, each day of the STEM camp, the youths along with us hosted two sessions of circle time, first at the beginning to orient and refine plans for the day, and second, to reflect on how their activities went and how to modify the next steps. Circle time offered one way of increasing possibilities for rightful presence by securing a daily routine practice in which educators and youths collaboratively engaged in conversation that often evolved to the ideas of exposing and seeking to resist against different forms of injustices operating at multiple scales of their lives. During the first circle time, youths referred to themselves as "youth mentors," those who are not just recipients of the program prescribed by educators but as active participants in program design. Accordingly, they also used circle time to author the norms of what it meant to be mentors and to reflect on educator-created activities, critiquing them and suggesting new activities and programs.

\subsection{Data Generation}

This study on a summer STEM camp in a community center draws on a larger research-practice partnership project that is investigating justice-centered approaches to STEM-rich maker education programs. Data sources included reflective conversations, educator portfolios of participatory design processes, and ethnographic documentation.

Reflective conversations. We utilized three forms of reflective conversation that were crucial to documenting our participatory process. They include daily reflective conversations with youths during circle time (video recorded, 15-20 minutes, 10 times), reflective conversations between the two educators at the end of daily sessions (audio recorded, 20-30 minutes, 7 times), and follow-up interviews with individual youth who volunteered (audio recorded, 15-20 minutes, with four youths).

Reflective conversations took place in daily circle times with the young people and were a crucial source of data: Circle time conversations provided us with initial guidance on which part of the data we would begin to look at for analysis of the participatory processes. We asked ourselves, educators and 
youths alike, questions regarding (1) the moments that stood out to us during the day and why and (2) how we wanted to revise the activity of the day or create new activities or programs and, if so, why.

Educator Portfolios. We, as educators, co-generated portfolios regarding the planning, implementing, and reflection of the sтем camp program. During the planning phase (four times, 2 hours each), we generated multiple versions of program outlines, resources, and materials prepared for and used in the sessions. Throughout the implementation and reflection phases, we took photos of moments and generated daily individual reflection notes as educators. We also kept youth-created STEM artifacts and their notes (drawings and annotations) generated during the circle time to express their critiques, questions, and suggestions to bring change in the STEM camp program.

Ethnographic Documentation. We also generated ethnographic field notes as researchers. We recorded our observations focusing on educator-youth interactions, youth engagement, and educator actions. We also kept information on attendance, the norms and routines of the programs, and materials.

\subsection{Data Analysis}

To examine how the youths made rightful presence visible and how we amplified it during the sтем camp, we attended to the moments that the youths and educator-researchers articulated during our reflective conversations, referring to ethnographic documents. By "moments" we refer to salient instances any participants reported in which a particular shift seemed to occur in discourse, practice, and/or relationality. We consider moments entry points to the insights we seek to notice, address, and transform (Luna, 2018).

We undertook comparative analysis, following the critical grounded theory tradition (Bryant \& Charmaz, 2007), which involves two iterative coding phases: open and axial coding. First, we open-coded for moments in which youths' bids for rightful presence were made visible during the camp. Initial identification of moments took place in the different forms of reflective conversations. Emergent open codes were kept with analytic memos, which informed the next phases to determine actions and interactions, impact, and context of the moments. This open-coding process led us to identify 16 moments (duration ranging from half of a minute to 10 minutes) that we considered youths' bids for rightful presence made visible.

In the second phase of coding, axial coding, we referred to the rightful presence and its tenets in order to identify the features identifiable across the moments. By looking at the open-coding analytic memo (from the first phase) with other ethnographic data, we identified the overlaps and disjunctures of the open codes that allowed us to initially group and extract different 
features the moments illustrated regarding the tenets of rightful presence (i.e., allied political struggles, rightfulness as presence, and collective disruption of guest/host relationality). To identify the features, we articulated three aspects observable from each moment: participants' discursive and embodied actions, tensions that arose from those actions and how the tensions were negotiated and transformed, and their impact on discourse and practices in the learning community.

\section{$4 \quad$ Moments of Making Visible and Amplifying Youths' Rightful Presence}

We explore three vignettes that illustrate the moments of making visible and amplifying the youths' rightful presence, in which the co-disruption of forms of injustice occurred. Disrupted forms of injustices we observed in the moments include those invisibly embedded in daily discourse and practices that delimit youths' rightful presence, such as educators' or community adults' deficitoriented assumptions of youths and the long-held narratives in STEM education positioning youths as knowledge recipients. We attended to how rightful presence was made visible and amplified, and in doing so what the youths and we as educators co-disrupted.

\subsection{Vignette 1. Seeing Upside Down}

The first vignette involves two connected moments that illustrate how youths' lives were made visible and amplified during the circle time. We suggest that the youths sought to re-author their rights for participation by spontaneously enriching and embodying investigation into science knowledge and practices (Tenet 1). In the vignette, we explain what happened in the moments and how we as educators responded to them.

The first moment of this vignette emerged from the first day circle time session held after the pinhole camera making activity. Won asked the youths to share what they had learned from making their cameras and observing through them, hoping to scaffold youths' understanding of the principle of light path and related natural phenomena. When asked to share their observations, Louise told the group that the pinhole camera produced a "weird upside-down picture." Won used Louise's observation to ask the youths "why" they thought the image was upside down. They discussed how the image goes upside down by collaboratively drawing the model of light path on the whiteboard (Figure 1a). 


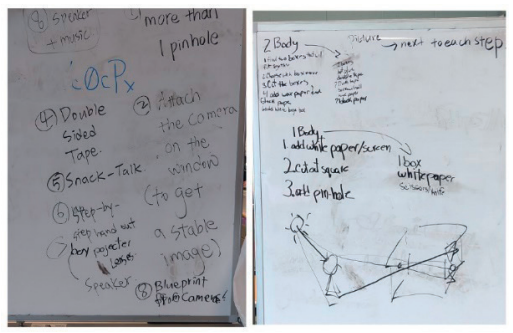

1a. Explaining the pinhole camera images using whiteboard

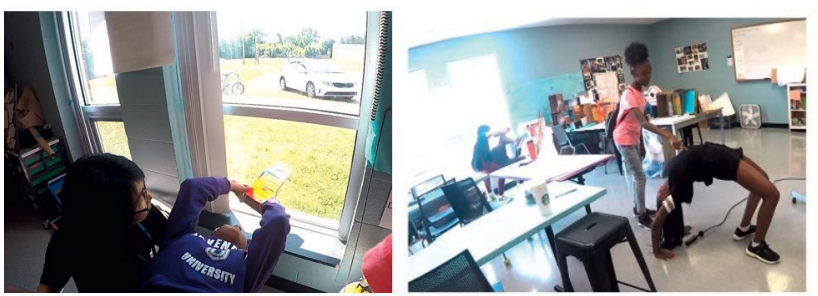

1b. Youths' embodied investigation of pinhole camera images

FIGURE 1 Youths' investigation of pinhole camera images

Louise then raised a question, which prompted the spontaneous investigation of pinhole camera images:

Louise: What if we were upside down? What would the image look like? Chloe: The image would be seen right-side up because we would be upside down.

Lele: I think it still would be seen upside down.

Chloe: Can you a do back bend? I can do it and see if it looks upside down or straight up.

Instead of waiting for Won to respond, Louise and Chloe held up their own pinhole cameras to test their ideas and began moving chairs and tables. They took up space with their bodies and movements. They used their gymnastics and cheer squad moves to investigate what happens to the image in the upsidedown posture. Other youths in the room joined in experimenting with different variables related to their camera use from how to view their image (e.g., upside down), to how close or far from the window and object they were, the size of the aperture, and the amount of light and darkness in the vicinity.

Angie also joined in and asked Chloe and Louise to show her how to do a backbend. When she struggled to do so, Chloe helped with a modified 
backbend using a chair as a support. Chloe and Louise cheered her on as she tried to use their ideas to view the image upside down (see Figure $1 b$ ). The space immediately became the site of investigation they had initiated. The youths did not just end up listening to Won's explanation of why the image looked upside down. They asked further questions and proposed answers. To investigate the answers, they freely moved their bodies across the room, and continued to experiment by using their own pinhole cameras.

During our reflective conversations after the camp, we recalled the moment as that of witnessing youths' bids for rightful presence. As the youths' embodied investigation indicated, they sought to make their lives and bodies matter in ISL. Won then recalled that her pedagogical talk-moves of asking "what they learned and what they observed" might have sounded as if confirming knowledge delivery, not facilitating the talk for participatory reflection of the day. She expressed the moment as her learning of the day, which came from acknowledging the gap between an educator's knowing what justice-oriented practices would look like and her enacting such practices in the moment-tomoment interaction.

When the youths rejoined the red couch after fulfilling their spontaneous pinhole camera investigation, Angie expressed joy and gratitude to Louise, Chloe, and other youths about asking the intriguing question and about Chloe helping Louise do the cheer squad moves. Won then asked them about the program co-designing and transformation. Enabling such instances required not just bringing activities thoroughly prepared by educators, but also foregrounding those that emerged by the youths in the moment as necessary and important in creating learning opportunities. Doing so worked toward disrupting the traditional way of engaging in science knowledge and practices and the narrative positioning youths as knowledge recipients.

The next moment illustrates educators' efforts to amplify youths' lived lives by seeking to revise and co-design the program activities. When the young people reconvened in circle time to reflect on the spontaneous investigation of the pinhole camera images, Won, in an effort to explicitly reflect youths' voices into the instructional plan and future implementation, asked the youths to provide feedback to improve the plan and activity sheets she had offered them. Youths offered critiques in depth about not only the words, expressions, and questions of the activity sheet, but also the formats and the ways in which the information for the activity was presented. Particularly, referring to their spontaneous investigation of the upside-down image through pinhole cameras, they suggested that Louise's question be discussed in the future sessions of making pinhole cameras. They also agreed that the activity sheet should offer youth-maker-friendly, step-by-step guidelines to make pinhole cameras. 
Angie asked the group to use the markers and the whiteboard to reconstruct the activity, inviting everyone at circle time to join in. Chloe, approaching the whiteboard, took the lead in the youths' collective document revision process, and other youths participated as well. Later when asked about the moments of the day, Chloe pointed out the moment in which she led the group to revise the program. She exclaimed, "this feels like we are real professionals!"

This moment captures how a STEM program initially developed by educators could be transformed by the youths' critical engagement in the program. Furthermore, as we expressed in the vignette, the youths taught us by taking actions that led to authentic scientific investigation, through which they made visible their rightful presence. Youths' actions in the moments made us reflect on educators' pedagogical talk-moves and more actively participate in the youths' political struggles to become rightfully present. Taken together, this vignette developed from youths' embodied investigation to the co-designing of the program storyline and exemplifies how collective disruption of traditional classroom relationality is enabled by all members of the learning community: educators and youths alike.

\subsection{Vignette 2. Foot's Point of View}

While the above vignette illustrates how the co-disruption for amplifying rightful presence can occur within a learning community, such a co-disruption often entails the tension felt by an educator intersecting with the institutional power structure. The second vignette explores two connected moments when the youths (and we as allies) navigated the tension of intersecting with institutional structure and relationality (Tenets 1 and 2).

The first moment of this vignette reveals how youths made visible their lived lives by revising the educator-presented idea to be directly relevant and meaningful to their lives. On the third day of the camp, Won suggested to the youths an idea of making a camera video-mounted remote control (RC) car. She asked the youths to try to make it so that (1) the mounts stably sit on the car so that the mounted camera would be safe wherever the RC car went, (2) the mounts are waterproof so that video/audio recording was possible even when it rained/snowed, and (3) the camera could be easily put in and pulled out without disassembling the whole mount. In doing so, Won hoped to engage the youths in recording the views at the height of small animals in support of youths using the video footage to see the world from an animal's point of view. The youths at first liked the idea of making the video-mounted RC car, as they could see the view of "dogs" or "rabbits," the animals they loved. They then shifted to imagine how the RC car may help them to record, as Su'Zanne put, their "foot's point of view" at the club. As Su'Zanne noted, their feet run all 
over the club every day. What would the feet see if they could see? What would they learn by looking at their club from this new perspective? After all, animals are not allowed inside the club.

They were excited about the idea of capturing the footage of the place explicitly relevant and meaningful to their lives, which we infer as youths' exercise for their rightful presence by relating their STEM artifacts to be explicitly grounded in their lived histories in the community center. As later stated during the circle time by Su'Zanne and Lele, taking the footage of the community center appeared to be more explicitly important to them than taking the animal's views. They were curious about what the view of their beloved space would look like from their feet's height. From their time in the center, they also had lived knowledge about the rooms they wanted to capture on video and what took place in those rooms. Furthermore, they sought to be recognized with their effort and design work by those who mattered to their lives: their friends and adults inside the community center.

We, educators and youths alike, thus shifted the project from taking small animals' views to taking their foot's views of the community center. Motivated by the shift, the youths seemed to be more actively engaged in rendering the RC car to have a video mount. For example, in addition to using a variety of materials to make a camera mount meeting the criteria we suggested, they added ideas to showcase nicely in front of others in the club. They eliminated the need to remove the camera from the mount and put it back in again every time. They started to examine the camera's operation settings and options. After a few minutes, Chloe called out, "[Camera] start." After a pause, the youths all shouted, "Yeah!" as they finally found the voice control working. They taught us how to start and stop using voice control. This voice control made their RC car operation easier to take their foot's point of view. It also showcased their authority as they directed their cars' movements with their voices as they roamed the center among their peers.

In the next moment, the youths sought to further publicize their lives and expertise by showcasing their STEM artifacts to those who mattered to them. When Lele and Su'Zanne completed their camera-mounted RC car, the youths wanted to drive it to other rooms in the center to take the foot's point of view. They told us that they also wanted to show how their artifact was "cool" to their "friends" and "Granny and Candace" (the elders of the center). This was particularly important as we wanted to reverse how Su'Zanne was often viewed as being disruptive and disengaged in the center.

However, at the same time, Won felt the tension inside as an educator. During our reflective conversations Won recalled: 
I saw they wanted to drive their RC car across the rooms. I also wanted people to see their accomplishments, like ... "this is Su'Zanne, whom you have not known yet!" However, what if we would be just seen as disturbing and in fact disturbing activities being held in other rooms? I never wanted them to be seen in that way. So, I frankly expressed both of my hope and concern to Su'Zanne and Lele. They then suggested an idea. They would only drive to the wide room in which youths can freely move around. They also wanted to show theirs to the elders in the center. So, we did. We tried to be safely testing it and recording videos from the foot's point of view.

As Won frankly shared with the youths the tension she encountered in the moment, the youths suggested a clear and wise solution while being respectful to her concern. They operated the car across the lobby, trying to ensure safety without disturbing other youths groups or staff. They first tested out their car to ensure stable operation.

When they found their mount working adequately, they started to video record the foot's point of view (Figure 2a). They ran the car towards one room. As the youths were allowed to freely navigate the room with their car, the girls operated it through the middle of their friends, who were impressed and excited by the two girls' showcasing. They turned the car on and off with their voices and let the RC car move below the table across their friends' feet. Coming out of the room, Su'Zanne and Lele moved on to show their artifact to two community elders: Granny, who was working in the kitchen, and Candace, the center's main director. When they reached the director's office, Candace came out and welcomed the youths (Figure 2b). She exclaimed with joy and excitement. Looking into the eyes of both Su'Zanne and Lele who were enthusiastically articulating the process of design and improvement, Candace smiled and told them, "That's amazing. I am so proud of you." The three of them hugged one another.

This vignette suggests how an educator can be a necessary ally and supporter of youths in navigating institutional power structures and allowable actions in the structure. This also illustrates tensions that she may feel when seeking to participate in disrupting normalized practices in ways that amplify youths' rightful presence. We tried to support the youths who pushed the boundaries and expanded the spaces where they could engage in STEM and be recognized as experts by those who mattered to them. Youths were welcomed as legitimate meaning makers. They sought to capture a "foot's point of view," including how to program the car to do so. They utilized the knowledge 


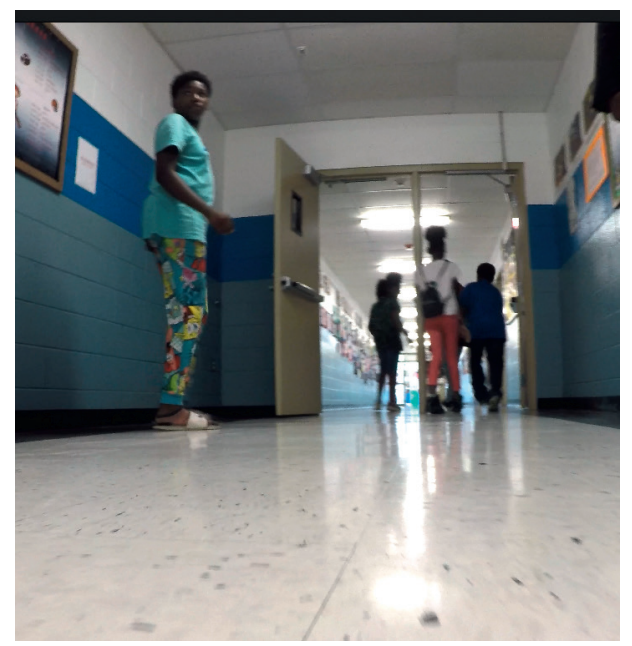

2a. Video-recording the foot's point of view
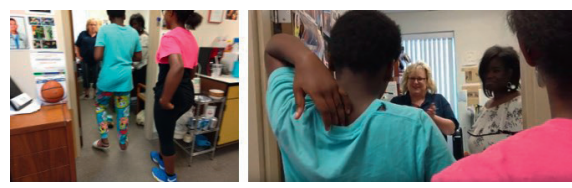

$2 b$. Visiting elders in the community center and showcasing their artifact

FIGURE 2 Su'Zanne and Lele taking foot's point of view and showcasing design artifacts

of where to go in the center. In doing so, they created opportunities to share their expertise and presence with community members, particularly in a way that disrupted the view held by some adult educators who consider Su'Zanne and her entrances into their space as a distraction.

\subsection{Vignette 3. Legitimizing a Friend's Expertise to Be Useful for the Community}

The third vignette illustrates how Won supported the youths in making visible and amplifying their rightful presence by allying with youths to publicly legitimize their peers' expertise as meaningful to the community (Tenets 2 and 3 ). However, in this vignette, the alliance did not come easily. Rather, it was through other youths who advocated their friends' expertise in ways that disrupted and transformed Won's limited view of what is considered to be expertise in STEM (Tenet 1). In doing so, the youths' varying knowledge, experience, and expertise contributed to rendering their STEM learning an expression of rightful presence. 
It was the last day of the camp. As we had already announced at the start of the camp, we used the early part of the last day to prepare for showcasing their GIS maps. GIS mapping was a culminating project in which youths used the images and videos taken from the artifacts and devices they investigated during previous days in order to illustrate their activities and routes in the community center, the place they pointed out as mattering to their present lives. Youths were making individualized G Is maps using the photos and videos they recorded and the stories they wrote. Each youths held an individual laptop to work on the project.

Su'Zanne and Lele were sitting side by side because they were working as a group to make a map together (Figure 3a), but Su'Zanne was interested more in different work: creating beats using a music production app. Won hoped the youths would engage equally in preparing for the showcase they had waited and planned for the previous 4 days. We were also concerned about whether Lele felt frustrated by having to work on the project without Su'Zanne's support. Even though Won acknowledged making and mixing music as an expertise, she was not sure at the moment if the expertise was useful to prepare for the last day showcase. She felt some degree of inner conflict about whether or not to intervene to reorient Su'Zanne to collaborate with Lele, not knowing how to support each of the youths. While the tensions in the above two vignettes were related to the norms and structure of STEM learning, the one in this moment felt tougher to Won because she had to be against what mattered to Su'Zanne at the moment.

Lele noticed her concern and shared her worry with Won:

Lele: Can Su'Zanne make some beats for us? You hear that sound over there she just made? I was just thinking, yesterday, we found our drone videos did not record the sound. It was all mute. What if we use Su'Zanne's music as background for the drone video?

Won: I appreciate that idea. It would be so cool we have our own music for the drone videos.

Lele: If we dub the music to the video, I want to have it linked to the map. Won: Can we add a link to the map? That is so cool. But, isn't it challenging for you alone to work on making the map? That is my only concern ....

Lele: Su'Zanne and I almost made ours. I am happy to handle the rest of it.

Su'Zanne: (from her table, still intensely focusing on her music production) I can make several ones for them (other youths in the room) and for the background music of the showcase. We need original music for us. 


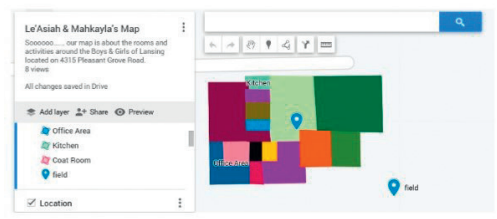

3a. Creating Gis maps
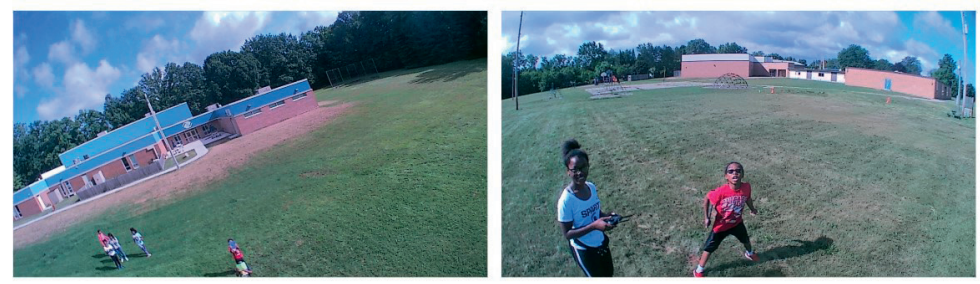

3b. Involving drone videos into GIS maps

FIGURE 3 Creating GIS maps of the community center using multiple images and videos

Won immediately reflected on it as a gentle but critical call for disrupting the ideas of what is legitimate action taken in the sт вм learning space. Lele acknowledged Su'Zanne's contribution and valued her knowledge and skills from what she loved to do (adding background music to the drone videos they took on the previous day, Figure $3 \mathrm{~b}$ ). It also presented a new technical challenge as the girls had to figure out how to dub the drone video and link the music to their Gis map. In doing so, Lele found a way to make her friend's talents address the needs of the community. Lele's brokering indicates how youths advocate for one another in ways that call attention to youths being rightfully present as fully contributing members because of who one is.

Accordingly, Won took up Lele's call and explicitly supported Su'Zanne to produce music. Lele taught Won how to recognize and leverage the practice, experience, and wisdom youths bring to the learning environment. Su'Zanne, when brokered and recognized as a contributing member by Lele, asked her for headphones so that her music work may not disturb other youths' showcase preparation (Figure 4a). This request for headphones caught our attention as Su'Zanne was previously turning the volume of the music she was working on up. One way to understand Su'Zanne's request for headphones is that Su'Zanne made her music louder as a form of resistance against the atmosphere likely to imply her music production as off task. When legitimized and supported 


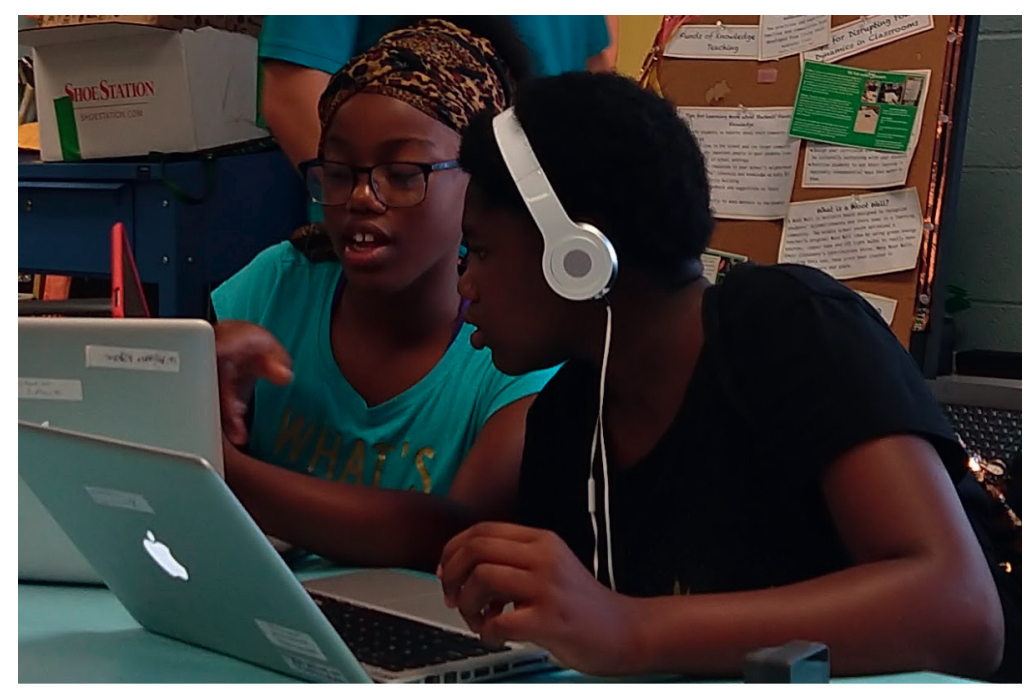

4a. Su'Zanne's music production
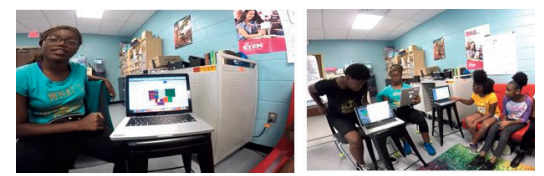

4b. Youths' the last day GIS map showcasing

FIGURE 4 Su'Zanne's music production and youths' GIS map showcasing

by Lele and then Won, Su'Zanne also became caring and supportive of others' works. She focused on music production and created several pieces of soft beats. The beats were used not only as background music of the drone videos and the youths' GIS map showcase but also as the music of the after-showcase party which spontaneously emerged (Figure $4 \mathrm{~b}$ ).

Won's presumption of legitimate ways of doing STEM was disrupted along with Lele's brokering and publicizing her friend Su'Zanne's expertise in music not as off task but as necessary to solve the problems identified. Furthermore, it was very clear how much Su'Zanne was immersed in her project and wanted to help others in the camp community.

To sum up, these three vignettes illustrate how rightful presence can be made visible and amplified through the community efforts of youths and educators seeking to co-disrupt traditional relationality, norms, and practices in their STEM learning space and as a larger community (Table 1 ). 


\begin{tabular}{|c|c|c|}
\hline Vignette $\begin{array}{r}\text { Research } \\
\text { Questions }\end{array}$ & $\begin{array}{l}\text { How do youths bid for a more } \\
\text { rightful presence in IS L? }\end{array}$ & $\begin{array}{l}\text { How do ISL educators } \\
\text { recognize and respond to such } \\
\text { bids? }\end{array}$ \\
\hline $\begin{array}{l}\text { 1. Seeing upside } \\
\text { down }\end{array}$ & $\begin{array}{l}\text { - Enacting embodied ways } \\
\text { of engaging in disciplinary } \\
\text { knowledge and practices } \\
\text { - Disrupting traditional } \\
\text { relationality positioning youths } \\
\text { as knowledge recipients }\end{array}$ & $\begin{array}{l}\text { - Supporting youth-initiated/ } \\
\text { embodied rigorous engagement } \\
\text { in disciplinary knowledge/ } \\
\text { practice } \\
\text { - Asking youths' input to } \\
\text { co-design the STEM program }\end{array}$ \\
\hline $\begin{array}{l}\text { 2. Foot's point of } \\
\text { view }\end{array}$ & $\begin{array}{l}\text { - Sharing authority with } \\
\text { educators as decision makers } \\
\text { - Disrupting deficit view that } \\
\text { some community members } \\
\text { had held on the youths }\end{array}$ & $\begin{array}{l}\text { - Foregrounding the practices } \\
\text { in the youths' lived lives and } \\
\text { social-spatial relationality } \\
\text { - Exhibiting youths' expertise } \\
\text { to those who mattered to youth }\end{array}$ \\
\hline $\begin{array}{l}\text { 3. Brokering a } \\
\text { friend's expertise }\end{array}$ & $\begin{array}{l}\text { - Questioning educator-held } \\
\text { norm of what is considered to } \\
\text { be expertise related to STEM } \\
\text { - Transforming educator-held } \\
\text { view of inter-youth } \\
\text { collaboration and relationship }\end{array}$ & $\begin{array}{l}\text { - Publicizing youths' } \\
\text { non-traditional expertise to be } \\
\text { relevant and useful } \\
\text { - Centering humanizing } \\
\text { relationship as an important } \\
\text { part of STEM learning }\end{array}$ \\
\hline
\end{tabular}

Across the three vignettes we see different instantiations of the three tenets of rightful presence in an imbricating manner. For Tenet 1, political struggle is integral to Sтем learning, we see how the youths and educators work together to re-author the rights related to participating in the STEM club. The youths suggested, challenged, and enacted new ways of being to test out and negotiate new rights. We see such attempts to re-author rights along a spectrum.

In Vignette 1, youths sought to extend an educator-sanctioned activity of investigating pinhole cameras by asking their own questions and using their out-of-STEM expertise - pliable cheerleader bodies and choreographic moves to make sense of scientific ideas. They shifted chairs and used their bodies in ways not necessarily expected by the educators, who nonetheless were fully 
supportive. In addition, Angie as an educator, further positioned the youths as experts by asking their advice on how to perform a back-bend and ceded the educator role to Chloe at the whiteboard. Collectively, youths and educators disrupted normalized adult-youth of knowledge deliverer/recipient hierarchies that nonetheless operate in the background. This is not because the educators of the STEM club are not already actively working to flatten these normalized hierarchies, but rather it is because of how historically entrenched these hierarchies are in governing learning settings involving adults and youths.

In Vignette 2, the youths rewrote the script for the activity, while keeping the main engineering tasks the same: changing the purpose from documenting a small animal's point of view to documenting their foot's point of view. While the technical aspects of the task remained, the social and political aspects were profoundly transformed. By tracking their foot's point of view, youths were literally making visible their routes and attending social relationships with this STEM activity. Beyond tracing well-trodden routes that make visible the where, when, why, and with whom of their presence at different spaces in the community center, youths actively and literally paved new routes that positioned them with more power with respected elders at the club: Granny and Candace. Not only were they able to "visit" the high-powered office of the director during sTEM programming, the youths rightfully earned Candace's admiration and recognition as developing STEM experts. Their physical presence (Tenet 2) in moving around the center spaces was intertwined with their authoring a new disciplinary presence by reframing the why of the task.

In Vignette 3, Su'Zanne's expertise in creating beats, what she described as "original music," that was recognized by peer Lele who advocated for Su'Zanne to work on the beats with Won, illustrates the interwoven nature of all three rightful presence tenets. Su'Zanne introduced and was supported first by Lele and then Won, another way of participating in the project that played up her talent and interest but also added to the projects of their peers. Her original music was not superfluous, instead her own expertise was afforded presence at STEM club, and her original music added further authenticity and ownership to the youths' projects about their lives at their club.

While we hope that these vignettes offer hopeful and concrete examples of how rightful presence in STEM in ISL can collectively be sought for, we emphasize, in equal measure, that seeking for rightful presence is hard, long-term work, fraught with tensions for all stakeholders involved. It has to be so, given the historic, baked-in systemic injustices in science learning. However, the local nature in which systemic injustices are manifested reminds us of the possibilities toward justice that can be enacted when we choose to center youths' 
voices and wisdom in a shared commitment to engage in political struggle towards rightful presence.

These vignettes also show the tensions educators encountered and navigated during the sтем camp. One of the tensions reflected the assumptions educators brought were sometimes in conflict with working toward rightful presence. For example, although Won had been committed to be an active and reflective supporter of youths' STEM learning, the discourse and assumptions she developed through her own lived experience as a teacher (e.g., the manner in which she led the circle time after pinhole camera activity) and a learner (e.g., expecting peers, to collaborate as she expected) were contested in the moments. The STEM camp exposed her to the questions and dilemmas coming from the conflict and how to continue to transform with youths her ways of viewing and enacting practices for youths' rightful presence.

Another important tension we negotiated came from our positionalities as experienced researcher-educator (Angie) and beginner (Won). Although we tried to be aware of power dynamics embedded in the different positions, our collaborative work required us to be honest and vulnerable to recognizing and reporting the dilemmas and questions coming from our engagement in this project. We often found subtle differences in our initial stance on equity and our understanding about the youths and their bids for rightful presence.

The difference appeared, for example, in our responses to Louise's question in the first vignette. Louise reported her observation of "weird" upside-down images through a pinhole camera and asked about positioning her own body upside down to see through the camera. Angie immediately participated in Louise-initiated embodied investigation. Won then sought to highlight Louise's observation of the pinhole camera and continue the discussion drawing on it. Here, we avoid judging educators' different responses with a deficit-oriented lens (i.e., comparing what is better or worse or what was wrong). Instead, we sought to understand our commitments that underlie the responses and leverage such differences to amplify our potential of working toward justice and youths' rightful presence.

To navigate the tensions that arose in moments like these, we mobilized and continued to develop politicized trust among the youths, the experienced, and beginning educators (researchers). Politicized trust means, "actively acknowledg[ing] the racialized tensions and power dynamics inherent in design partnerships" (Vakil et al., 2016, p. 199). The concept of politicized trust is particularly important in projects seeking to disrupt and transform traditional power asymmetries that can exist in the researcher/researched and experienced/beginner researcher relationships. The power asymmetries intersect with collaborators' racial differences and their raced experiences. 
Calling out differences in power and race would entail awareness and acknowledgement of fragility and vulnerability in the dynamics of power and race as part of politicized trust in critical justice-oriented collaborative work (Vakil et al., 2016).

With regard to Tenet 3, collective disruption of guest (youth)/host (adult mentors such as educators and researchers) power dynamics is not a straightforward process. Adult mentors need a foundational base of strong relationships with the youths before youths will endeavor to enact bids for rightful presence. Adult mentors also need a nuanced understanding of the possibilities that active participation in the STEM programming could look like in order to facilitate the recognition of youths' novel bids. How entrenched power dynamics might intersect with cultural norms is also a necessary consideration. In societies that emphasize and strongly adhere to hierarchical ranks as a show of respect, collective disruption of guest/host power dynamics would be a more challenging issues.

Our discussions on how youths bid for rightful presence and how educators respond and amplify the bids indicate that working toward rightful presence requires collective efforts. Such efforts can be facilitated by conducting participatory design research based on politicized trust among research participants whose cultural background, race, and positions in power relationalities might differ, and tensions often come about due to the differences.

Relating our findings and discussions to the main audience of this journal, we suggest for those interested in justice-oriented science education research in the Asia-Pacific region: rightful presence as a pedagogical framework and participatory design as a methodological approach to implementing programs based on the pedagogical framework. As Martin (2020) argues in this journal, there is an urgent need to "amplify the voices of researchers from countries not traditionally included in mainstream science education journals" (p. 3). Science education practice and research in the Asia-Pacific region has huge potential to enlighten and inform those across the world. Particularly, investigating how science education in this region has considered educational (in) justice at its practice and research will contribute to enrich and complicate the worldwide discourse of justice-oriented science education. Indeed, there have been prior studies oriented in this direction. Martin and Kang (2018) attended to Korean secondary science teachers' "experiential learning with SEN [special education needs] students during authentic science teaching activities" in the South Korean context (p. 101). Hwang (2018), by reviewing literature of equity-oriented science education research, calls for sociocultural approaches to realize more inclusive and equitable science education in both formal and informal contexts in South Korea. 
Our study then pushes such inspirational efforts further to place an explicit attention to structural (in)justices, how educators' pedagogical practices mediate the (in)justices, and how educator-researcher partnerships can disrupt inequitable and unjust historical narratives that may have shaped pedagogical discourse, practices, and decisions. Without addressing the issues of injustices embedded in daily discourse and practices of educational spaces, efforts for equitable science education are insufficient (Calabrese Barton \& Tan, 2020a). Our findings zoom into a set of examples of what educator (researcher)-youth collaborative work toward justice would look like. We also acknowledge the sociohistorical and cultural differences that would create different forms of practices and interactions, particularly in the Asia-Pacific region. This underexamined area of research calls for more contextualized and more justiceoriented science education research in this region.

Designing for rightful presence in ISL is an important approach to re-mediating the ISL infrastructure that limits participation in science among historically marginalized youths. Such design efforts need to make visible, disrupt, and transform dominant unjust power relations that hierarchically position White ideologies as the norm. This involves flattening knowledge and power hierarchies through valuing discourses, practices, and forms of representation that reflect the lives of those made missing by historicized oppressions, as we have sought to do.

It was through the practices and stance oriented to rightful presence that enabled the educators and youths as allies to navigate emerging tensions and disrupt norms and practices manifested at the moment and over time. As creators of their own stories of ISL, youths capably represented themselves and those who they cared for with their educators who sought to support and amplify youths' urgent bids for rightful presence. However, for many youths without critical allies, gaining rightful presence in STEM learning spaces will remain a challenge.

Collective efforts are required to make present and center youths' lives, communities, histories, presents, and hoped-for futures as integral to reimagining what engaging with science is and could be. Foregrounding and amplifying the opportunities youths deserve, however, does not just come spontaneously. Rather, it requires critically and deliberately designed principles of justiceoriented pedagogical practices and the coalition of youths and educators by positioning themselves as co-learners, co-disruptors, and co-creators of a more just world with and in ISL. 


\section{Acknowledgements}

The authors would like to thank the youths who collaborated with us in this study. The authors would also like to thank the National Science Foundation for support of this research.

\section{Funding}

NSF DRL \#1712834.

\section{Ethical Considerations}

Approval to conduct this study was granted by the University of Michigan's and Michigan State University's Ethics Review Boards. The data collected from this project were obtained with the necessary clearance from the partner institutions, guardians, and the students involved in the study. The names of the school and participants used in this study are all pseudonyms. We obtained permission to use participant images in publications.

\section{About the Authors}

Angela Calabrese Barton is Professor in STEM Education and the Learning Sciences in the Department of Educational Studies at the University of Michigan. She received her Bachelor of Science Degree in Chemistry from the University of Notre Dame in South Bend, Indiana, in the United States, and her PhD from Michigan State University in East Lansing, Michigan, also in the United States. Her research focuses on issues of equity and justice in STEM education in both school and community settings. She studies both the design of learning environments, including pedagogies and approaches in support of justice-centered expansive learning outcomes such as critical agency, identity work, and social transformation (as grounded within expanding disciplinary expertise), and methodologies for embracing authentic "research + practice" work that attends to practitioner and youths voices and critically engages the goals of equity and justice. A former chemistry teacher, she has also designed and taught community-based ST EM for over two decades in homeless shelters and community organizations in different cities in the US. Calabrese Barton has served as a wT Grant Foundation Distinguished Fellow and is a Fellow of the American Education Research Association. She is currently Co-Editor 
of the American Educational Research Journal and is the former Co-Editor of the Journal of Research in Science Teaching. Calabrese Barton's work has been funded by the National Science Foundation, the Spencer Foundation, and the WT Grant Foundation, among others.

Won Jung Kim is a doctoral student in the Department of Curriculum, Instruction, and Teacher Education at Michigan State University in East Lansing, the United States. Her research focuses on supporting youths' equitable engagement with science/sT EM, seeking ways of implementing justice-oriented pedagogy for youths, particularly those from underserved communities. She is also interested in embodied sтем learning/living (e.g., dance, rap, performance, and social action) based on her precious twelve years of science teaching in South Korea and her trust in the power of multiple ways of knowing, learning, and being.

Edna Tan is Professor of Science Education at the University of North Carolina at Greensboro. Her collaborative research investigates what constitutes equitable and consequential science and engineering learning for historically underrepresented, minoritized youths, including recently resettled refugee youths, across learning contexts and over time. She investigates how systemic injustice is made manifest in local practices and the related impact of such oppressive local practices on youths' science and engineering learning experiences. Her work is also focused on understanding how youths' experiences across science-related settings and across time can be studied and understood as holistic experiences, rather than siloed in particular formal or informal settings. Her research has been published in the American Educational Research Journal, Teachers College Record, the Journal of the Learning Sciences, Journal of Research in Science Education, and Science Education, among others.

\section{References}

Archer, L., Dawson, E., Seakins, A., DeWitt, J., Godec, S., \& Whitby, C. (2016). 'I'm being a man here': Urban boys' performances of masculinity and engagement with science during a science museum visit. Journal of the Learning Sciences, 25(3), 438-485. doi: 10.1080/10508406.2016.1187147.

Bevan, B., Calabrese Barton, A., \& Garibay, C. (2018). Broadening perspectives on broadening participation in STEM. Washington, DC: Center for Advancement of Informal Science Education. 
Birmingham, D., Calabrese Barton, A., McDaniel, A., Jones, J., Turner, C., \& Rogers, A. (2017). 'But the science we do here matters': Youth-authored cases of consequential learning. Science Education, 101(5), 818-844. doi:10.1002/sce.21293.

Bryant, A., \& Charmaz, K. (2007). The SAGE handbook of grounded theory. SAGE Publications.

Calabrese Barton, A., \& Tan, E. (2010). We be burnin'! Agency, identity, and sciencelearning. Journal of the Learning Sciences, 19(2), 187-229. doi:10.1080/10508400903530044.

Calabrese Barton, A., \& Tan, E. (2020a). Beyond equity as inclusion: A framework of "rightful presence" for guiding justice-oriented studies in teaching and learning. Educational Researcher, 49(6), 433-440. doi:10.3102/o013189X20927363.

Calabrese Barton, A., Kim, W., Balzer, M., \& Brien, S. (2020b). Reclaiming the science center: Working towards social spatial justice. Paper presentation at the International Conference of the Learning Sciences. Virtual due to Covid-19, Nashville, TN.

Dawson, E. (2014). Equity in informal science education. Studies in Science Education, 5o(2), 209-247. doi:10.1080/03057267.2014.957558.

DeWitt, J., \& Archer, L. (2017). Participation in informal science learning experiences: the rich get richer?. International Journal of Science Education, 7(4), 356-373. doi: 10.1080/21548455.2017.1360531.

Feinstein, N. W. (2017). Equity and the meaning of science learning: A defining challenge for science museums. Science Education, 101(4), 533-538. doi:10.1002/sce.21287.

Greenberg, D. (2019). Critical participatory explorations of youth STEM pathways. Michigan State University, Educational Psychology and Educational Technology.

Gutiérrez, K. D., Cortes, K., Cortez, A., DiGiacomo, D., Higgs, J., Johnson, P., Lizárraga, J. P., Mendoza, E., Tiem, J., \& Vakil, S. (2017). Replacing representation with imagination: Finding ingenuity in everyday practices. Review of Research in Education, 41(1), 30-6o. doi:10.3102/oog1732X16687523.

Hwang, S. (2018). Research trend on the sociocultural approaches to science learning identity for the realization of 'Science Education for All'. Journal of the Korean Association for Science Education, 38(2), 187-202.

Kim, W. J., Calabrese Barton, A., Brien, S., \& Balzar, M. (2019). Youth-initiated moment of disrupting and restructuring authority. Proceedings of the European Science Education Research Association. Bologna, Italy: ESERA.

Luna, M. J. (2018). What does it mean to notice my students' ideas in science today?: An investigation of elementary teachers' practice of noticing their students' thinking in science. Cognition and Instruction, 36(4), 297-329. doi:10.1080/073700o8.2018 .1496919 .

Martin, S. N., \& Kang, D. Y. (2018). Exploring the transformative potential of experiential learning: Fostering positive attitudes towards inclusive science education for Special Education Needs (SEN) learners in Korea. In Critical Issues and Bold Visions for Science Education (pp.101-122). Leiden: Brill Sense. doi:10.1163/9789004389663_oo6. 
Martin, S.N.(2020). Asia-Pacific Science Education(APSE): Challenged to lead in uncertain times. Asia-Pacific Science Education, 6(1), 3-13. doi:10.1163/23641177-BJA1ooo3.

Rahm, J. (2010). Science in the making at the margin: A multisited ethnography of learning and becoming in an afterschool program, a garden, and a math and science upward bound program. In Science in the Making at the Margin (pp. 297-312). Leiden: Brill Sense.

Ryoo, J. J., \& Kekelis, L. (2016). STEM-rich and equitable making: Lessons from a museum-based research-practice partnership. Dimensions, 45-51. https://www .exploratorium.edu/sites/default/files/pdfs/2016_JulyAug_Dimensions_RyooKe kelis.pdf.

Shea, M. V., \& Sandoval, J. (2019). Using historical and political understanding to design for equity in science education. Science Education, 104(1), 27-49. doi:10.1002/ sce.21555.

Tan, E., Barton, A. C., Turner, E., \& Gutiérrez, M. V. (2012). Empowering science and mathematics education in urban schools. University of Chicago Press.

Tedesco, D., \& Bagelman, J. (2017). The 'missing' politics of whiteness and rightful presence in the Settler Colonial City. Millennium, 45(3), 380-402. doi:10.1177/ o305829817712075.

Tuck, E. (2009). Suspending damage: A letter to communities. Harvard Educational Review, 79(3), 409-428. doi:10.17763/haer.79.3.noo16675661t3n15.

Vakil, S., McKinney de Royston, M., Nasir, N., \& Kirshner, B. (2016). Rethinking race and power in design-based research. Cognition and Instruction, 34(3), 194-209. doi: 10.1080/07370008.2016.1169817.

Villenas, S. A. (2019). Pedagogies of being with: Witnessing, testimonio, and critical love in everyday social movement. International Journal of Qualitative Studies in Education, 32(2), 151-166. doi:10.1080/o9518398.2018.1533148.

Zavala, M. (2016). Design, participation, and social change: What design in grassroots spaces can teach learning scientists. Cognition and Instruction, 34(3), 236-249. 